\title{
PHOTOCATALYTIC OXIDATION OF LANDFILL LEACHATE USING UV/TiO2 WITH CATALYST RECOVERY
}

\author{
Neil Coffman ${ }^{1}{ }^{凶}$, Daniel Meeroff ${ }^{1}$, Frederick Bloetscher ${ }^{1}$ \\ ${ }^{1}$ Florida Atlantic University, Florida
}

DOI: https://doi.org/10.29121/ijetmr.v7.i8.2020.735

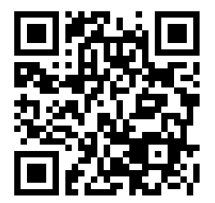

Article Citation: Neil Coffman, Daniel Meeroff, and Frederick Bloetscher. (2020). PHOTOCATALYTIC OXIDATION OF LANDFILL LEACHATE USING UV/TiO2 WITH CATALYST

RECOVERY. International Journal of Engineering Technologies and Management Research, 7(8), 21-34. https://doi.org/10.29121/ijetmr.v7 i8.2020.735

Published Date: 20 August 2020

Keywords:

Leachate

Oxidation Titanium Dioxide

Photocatalytic

\section{ABSTRACT}

This project evaluated the use of titanium dioxide for leachate treatment and recovery of methods for TiO2, using a TiO2 recovery technology, which was high enough to be economical $(\$ 10$ - $\$ 15$ per 1,000 gallons) to be adopted by wastewater treatment plants. When comparing recovery technologies, the three which were investigated further through experimentation were a centrifuge, sedimentation tank, and microfilter membrane. Upon experimentation and research, the TiO2 recovery efficiencies of these technologies were 99.5\%, 92.5\%, and 96.3\%, respectively. When doing economic analysis on these technologies comparing $\mathrm{TiO} 2$ efficiencies and capital and operational costs, the centrifuge was the most preferred economic option. It was found that costs were in the economical range ( $\$ 10-\$ 15 / 1,000$ gallons). TiO2: settling behavior, particle size and zeta potential, interactions with COD, and filter operations (particle characterization) were discovered for future research and future testing on this issue.

\section{INTRODUCTION}

Leachate is generated when water percolates through a landfill via surface runoff. This liquid is comprised of organic and inorganic contaminants, salts, nutrients, ammonia, toxic chemicals, and heavy metals, which have been suspended or dissolved in relatively high concentrations (McBarnette, 2011). Because of the potential water quality impacts to underground and aboveground sources of drinking water identified as a part of the Clean Water Act, landfills have been required to prevent leachate from being released into the environment by using liner systems underneath landfills. These liners contain the leachate and direct it to a leachate collection system for proper treatment prior to disposal.. Disposal of leachate generally involves on-site storage, on-site treatment, off-site discharge, discharge to a wastewater treatment plant, or deep well injection depending on availability locally.

The quantity of leachate that is formed depends on the amount of external water entering the landfill, the type of landfill construction (degree of compaction), landfill age (degree of decomposition), landfill size (physical area), waste composition (type of waste disposed and moisture content), inflows (surface runoff, infiltration, and ground water intrusion), and climatic conditions (rainfall, humidity, temperature, evaporation, evapotranspiration) (Lema et al., 1988; Méndez-Novelo et al., 2005; Renou et al., 2008). In 2010, Meeroff and Teegavarapu (2010) surveyed 31 landfill facilities in Florida and queried them about their leachate generation rates. Leachate flows ranging from less than 100 to about 3,000 gallons per day per acre (gpd/acre) were reported. Table 1 shows the results by landfill size.

(C) 2020 The Author(s). This is an open access article distributed under the terms of the Creative Commons Attribution License, which permits unrestricted use, distribution, and reproduction in any medium, provided the original author and source are credited. 
Table 1: Survey Leachate Generation Rates (McBarnette, 2011)

\begin{tabular}{|c|c|c|}
\hline Class & Range (gpd/acre) & Number of landfills \\
\hline Small & $<100$ & 14 \\
\hline Medium & $100-300$ & 9 \\
\hline Large & $300-850$ & 6 \\
\hline Super & $>850$ & 2 \\
\hline
\end{tabular}

The major issue with leachate management is the potential contamination of surface water, groundwater and underground sources of drinking water by the constituents typically found in landfill leachate. Important constituents include: i) dissolved organic matter from methane (CH4) to volatile fatty acids (VFA) to more refractory humics and fulvics; ii) inorganic constituents, such as sodium $(\mathrm{Na}+)$, potassium $(\mathrm{K}+)$, ammonium (NH4+), iron $(\mathrm{Fe} 2+$ ), manganese ( $\mathrm{Mn} 2+$ ), chlorides ( $\mathrm{Cl}-$ ), sulfates (SO42-) and heavy metals (arsenic, cadmium, chromium, cobalt, copper, lead, mercury, nickel and zinc), and iii) xenobiotic organic compounds from domestic and industrial sources, comprised of a broad variety of aromatic hydrocarbons, phenols, endocrine disrupting compounds (EDCs), pharmaceuticals, personal care products, pesticides, and chlorinated aliphatics among more than 100 other hazardous chemicals that have been isolated and identified in landfill leachate (Foo and Hameed, 2009). Table 2 provides typical ranges for leachate quality found in the literature.

Table 2: Typical Leachate Quality of Selected Constituents Based on Literature Review (Meeroff and Lakner 2014 and references therein)

\begin{tabular}{|c|c|c|c|}
\hline & & \multicolumn{2}{|c|}{ Concentration $\mathrm{mg} / \mathrm{L}$} \\
\hline Parameter & $\begin{array}{c}\text { Typical Wastewater unless otherwise } \\
\text { noted }\end{array}$ & Range & Average \\
\hline Ammonia mg/L as $\mathrm{NH}_{3}-\mathrm{N}$ & 40 & BDL - 13,000 & 1,100 \\
\hline Chemical Oxygen Demand (COD) $\mathrm{mg} / \mathrm{L}$ as $\mathrm{O}_{2}$ & 240 & $0.4-152,000$ & 8,750 \\
\hline $\begin{array}{l}\text { 5-day Biochemical Oxygen Demand }\left(\mathrm{BOD}_{5}\right) \\
\mathrm{mg} / \mathrm{L} \text { as } \mathrm{O}_{2}\end{array}$ & 200 & BDL $-80,800$ & 3,100 \\
\hline Total Suspended Solids (TSS) & 200 & $10-45,000$ & 4,604 \\
\hline Calcium $\left(\mathrm{Ca}^{2+}\right)$ & 50 & $200-8,600$ & 7,412 \\
\hline Magnesium $\left(\mathrm{Mg}^{2+}\right)$ & 15 & $2550-2,612$ & 1,962 \\
\hline pH (standard units) & $6.5-8$ & $2.0-11.3$ & 7.73 \\
\hline Total Dissolved Solids (TDS) & 500 & $0.1-88,000$ & 11,100 \\
\hline Alkalinity $\mathrm{mg} / \mathrm{L}$ as $\mathrm{CaCO}_{3}$ & 100 & $\begin{array}{l}3,300- \\
11,000\end{array}$ & 9,640 \\
\hline Lead $(\mathrm{Pb})$ & $<0.01$ & $\mathrm{BDL}-5.0$ & 0.41 \\
\hline Mercury (Hg) & $<0.01$ & $0.01-3$ & 0.5 \\
\hline Arsenic (As) & $<0.01$ & $0.1-1.682$ & 1.328 \\
\hline Sodium $\left(\mathrm{Na}^{+}\right)$ & & $200-7,769$ & 6,109 \\
\hline Chloride $\left(\mathrm{Cl}^{-}\right)$ & 50 & $100-11,538$ & 8,971 \\
\hline Color Platinum-Cobalt Units & 30 & $\begin{array}{l}3,530- \\
40,000\end{array}$ & 3,630 \\
\hline
\end{tabular}

Source: http://www.fao.org/3/t0551e/t0551e03.htm

$\mathrm{BDL}=$ below detectable level

As can be seen from Table 2, many of the water quality parameters are highly variable with relatively high concentrations compared to typical raw wastewater (Qasim, 2000, Meeroff, 2013; Youngman, 2013).

In locations where deep injection wells are not feasible and the landfill is relatively near to a wastewater treatment plant capable of assimilating the leachate without disrupting the biological treatment process, a common option for leachate management is to discharge directly to the municipal sewer system. The main challenge is the ability of the WWTP's biological process to handle the variable volume and water quality of the leachate in order to avoid disrupting the treatment process efficiency and the effluent water quality to be discharged. The best way to 
accomplish this solution iis when the leachate flow can be equalized across the day and the the municipal sewer system flows greatly exceed the leachate flows.

However, for cases where the mass balance of the municipal wastewater is affected by being blended with leachate, options for pretreating leachate prior to sewer discharge are needed. Advanced oxidation processes (AOPs) are methods that promote the creation of and utilize highly reactive oxidants such as hydroxyl radicals, ozone, and chlorine among others (Table 3). These oxidation reactions produce radicals, which are chemical species that possess an unpaired electron, causing them to be very unstable. The unstable radicals attempt to stabilize themselves by reacting with surrounding species. The radicals will continue to react with substances until stability is reached. Within milliseconds (Peyton and Glaze, 1988, cited by Fang et al., 2005), hydroxyl radicals are capable of achieving complete mineralization (i.e. degradation of complex organics to CO2, H2O, and mineral ions) of virtually all organic compounds (Feitz et al. 1999; Cho et al. 2002) rather than concentrate or transfer contaminants into a different phase. In this manner, pollutants that are only partially oxidized are decomposed into components that are more readily biodegradable and less toxic to common microorganisms found in a wastewater treatment plant for instance (Schulte et al. 1995; de Morais and Zamora 2005).

Table 3: Relative Oxidation Power of Selected Oxidizing Species (Munter et al., 2001)

\begin{tabular}{|c|c|c|}
\hline Oxidation Species & Symbol & Relative Oxidation Power \\
\hline Positively Charged Hole on Titanium Dioxide & $\left(\mathrm{h}^{+}\right)$ & 2.35 \\
\hline Hydroxyl radical & $\left(\mathrm{OH}^{-}\right)$ & 2.05 \\
\hline Ozone & $\left(\mathrm{O}_{3}\right)$ & 1.52 \\
\hline Hydrogen Peroxide & $\left(\mathrm{H}_{2} \mathrm{O}_{2}\right)$ & 1.31 \\
\hline Permanganate & $\left(\mathrm{MnO}_{4}\right)$ & 1.24 \\
\hline Hypochlorous Acid & $(\mathrm{HOCl})$ & 1.10 \\
\hline Chloride & $\left(\mathrm{Cl}_{2}\right)$ & 1.00 \\
\hline
\end{tabular}

One proposed solution is photocatalytic oxidation. A catalyst is an additive that allows a chemical reaction to occur at a faster rate without being used up in the reaction by reducing the activation energy (Hemond and FechnerLevy, 2015). Figure 1 demonstrates this concept.

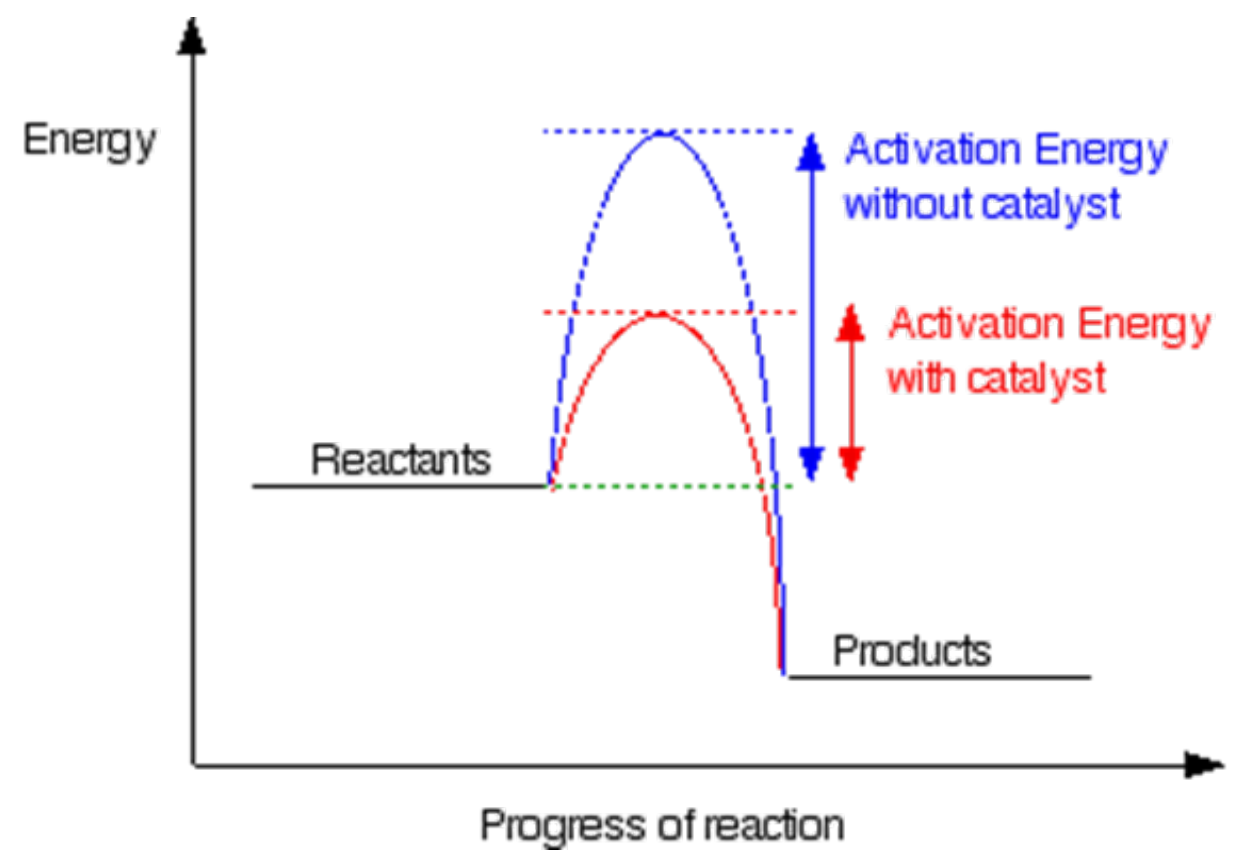

Figure 1: Catalyst Activation Energy

Source: http://www.chemguide.co.uk/physical/basicrates/catalyst.html 
One promising version of photocatalytic oxidation uses ultraviolet (UV) light and titanium dioxide (UV/TiO2) (McBarnette, 2011 and Youngman, 2013). TiO2 is a noncombustible, white, crystalline powder photocatalyst, activated by UV light. Previous research at Florida Atlantic University (FAU) using TiO2 to treat leachate has been shown to be effective at removing certain water quality parameters such as: color, metals and hardness, and TDS, but less effective at removing COD and ammonia (NH3) (McBarnette, 2011; Youngman, 2013; Lakner, 2015). One goal of this project was to evaluate the removal of OCD and ammonia while determining the recovery of the TiO2 because for the process to be cost effective, the TiO2 must be recoverable. Therefore, a second goal of this project was to determining how much $\mathrm{TiO} 2$ can be recovered after chemical reactions with the leachate such that the photocatalyst can be reused for subsequent batch reactions. It has been shown that $90 \%$ or more of the TiO2 that is used needs to be recovered for it to be considered economical and used for future treatment reuse (Meeroff, 2010). As a result, objectives are: (1) to determine the bench scale Ti02 recovery efficiency of centrifugation, sedimentation, and filtration; (2) to characterize the recovered TiO2 particles; (3) to develop preliminary scale-up parameters for design of each of the recovery technologies for economic analysis purposes.

\section{METHODOLOGY}

Leachate that was tested for treatment was collected from two urban landfills in Florida. Samples of different leachates were tested in the FAU Laboratories for Engineered Environmental Solutions (Lab.EES; http://labees.civil.fau.edu) to determine the key water quality parameters, particularly COD and NH3, since those were among the most difficult contaminants to remove. The testing method for COD was the reflux colorimetric method for measuring COD (ASChE, 2011). The testing method for NH3 was the EPA Method \#350.2 (Detection of Ammonia by Colorimetry), Nessler spectrophotometric method (Meeroff, 2014). The average COD and NH3 from the raw leachate was determined to be approximately $2,000 \mathrm{mg} / \mathrm{L}$, and 1,700 $\mathrm{mg} / \mathrm{L}$, respectively. The Degussa Aeroxide Ti02 P-25 product was used for all experiments.

Bench scale testing was performed on the leachate using the photocatalysis method of advanced oxidation. The leachate was mixed with TiO2 at different TiO2 doses ranging from $0.2-10 \mathrm{~g} / \mathrm{L}$. The mixture was then recirculated through a UV lamp falling film reactor. Figure 2 shows an example of this reactor.

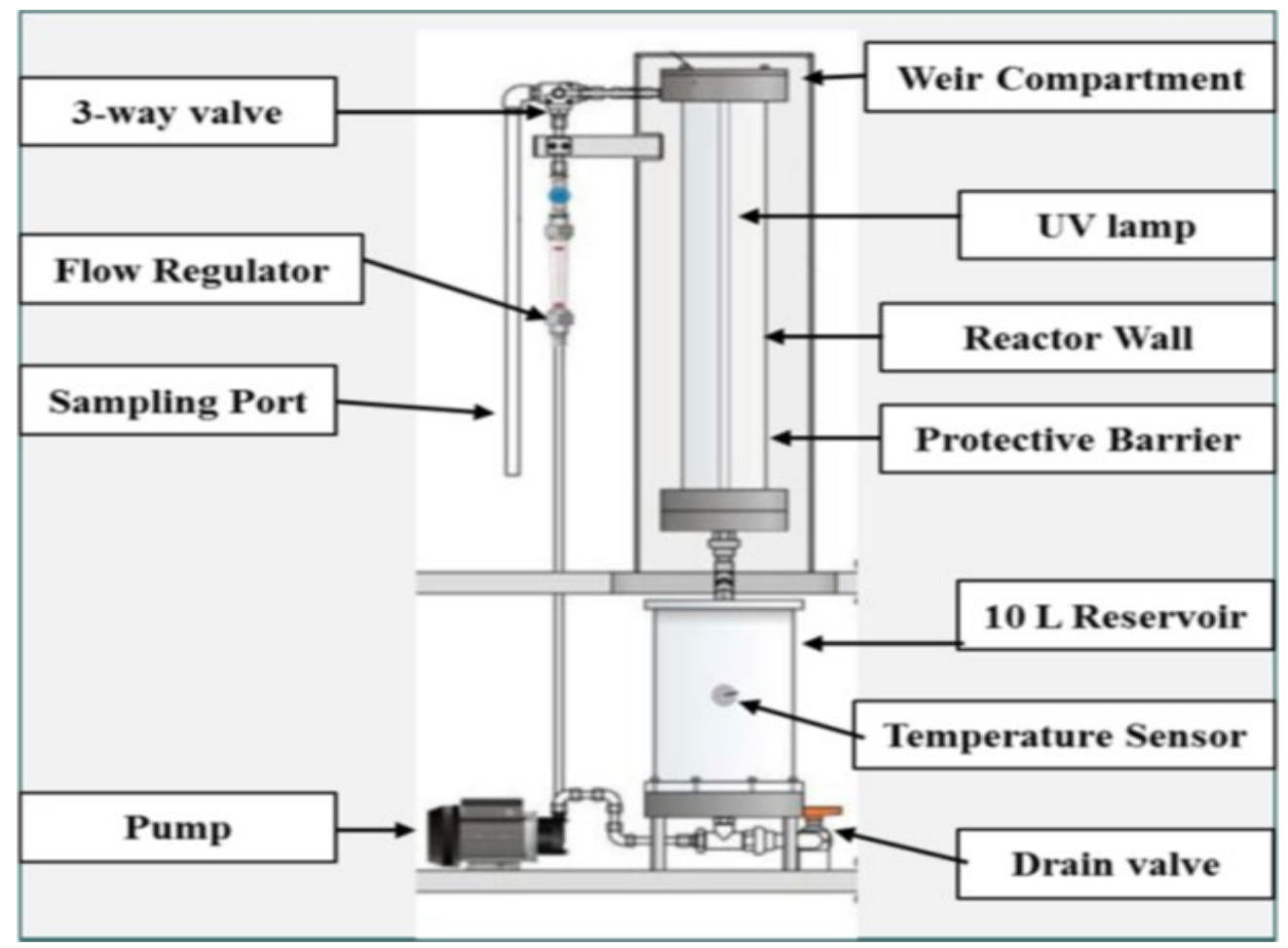

Figure 2: UV Lamp Falling Film Reactor (Meeroff, 2014) 
Neil Coffman, Daniel Meeroff, and Frederick Bloetscher

The unit is equipped with a 10 - $\mathrm{L}$ reservoir, temperature sensor $\left(0-50^{\circ} \mathrm{C}\right), 260 \mathrm{Lph}(1.1 \mathrm{gpm})$ circulating centrifugal pump at $9 \mathrm{~m}(29.5 \mathrm{ft})$ of head, flow meter with regulating valve, sampling port with three-way valve, and weir compartment for distributing flow in the reaction zone. The unit was operated in two modes: 1) recirculating falling film reactor or 2) recirculating flow-through reactor.

To operate as a falling film reactor, 8 liters of leachate was added to the 10-L reservoir. The UV source was started, and the leachate was then pumped up through the flow regulator to a three-way valve, which leads to either the sampling port or the weir compartment. The liquid was distributed in an even sheet via an overflow weir onto the cylindrical reactor wall, which surrounded the UV lamp. While the liquid ran down the reactor wall, it was exposed to UV radiation and then captured in the reservoir for recirculation. Once the leachate started to circulate, the desired amount of TiO2 (between $0.2-10 \mathrm{~g} / \mathrm{L}$ ) was added. The TiO2 is hydrophobic, so a small amount of leachate from the discharge port was added to a $250 \mathrm{~mL}$ beaker containing the TiO2 to make a slurry that was then added directly to the reservoir (Meeroff, 2014).

To operate as a flow-through reactor, a ball valve was attached to the reactor chamber drain line, which was partially closed to allow the liquid to build up in the reactor chamber. In this configuration, the leachate accumulated in the reactor chamber surrounding the UV lamp, instead of spilling down the walls in a thin sheet. The valve was set to allow the leachate to slowly drain through the reactor chamber where it was exposed to UV radiation before passing back through the ball valve and discharging into the reservoir.

Two different light sources were used: 1) 150-W Heraeus Noblelight NNI 125/84 XL with irradiance at $254 \mathrm{~nm}$ of $0.35 \mathrm{~mW} / \mathrm{cm} 2$ and radiation flux at $254 \mathrm{~nm}$ of $38 \mathrm{~W}$, and 2) 450-W Ace Glass Inc. medium pressure, quartz, mercury-vapor lamp. The formula below shows the calculation for UV light intensity, and Table 4 shows a comparison of the two UV lamps.

$$
\begin{aligned}
\text { Light Intensity }\left(\frac{\mathrm{W} \times \mathrm{hr}}{\mathrm{L}}\right) \\
=\text { Exposure Area }\left(\mathrm{cm}^{2}\right) \times \text { Measured Intensity }\left(\frac{\mathrm{W}}{\mathrm{cm}^{2}}\right) \\
\times \text { Retension time }\left(\frac{\text { Pass }}{\mathrm{L} \times \mathrm{hr}}\right) \times \text { Exposure Time }(\mathrm{hr}) \\
\times \text { Total Duration }(\mathrm{hr})
\end{aligned}
$$

Table 4: Measured UV Light Intensity (Meeroff, 2014)

\begin{tabular}{|c|c|c|}
\hline Light Source & UV-A\&B & UV-C \\
\hline $150-\mathrm{W}$ & $0.52 \mathrm{~mW} / \mathrm{cm}^{2}$ & $7.21 \mathrm{~mW} / \mathrm{cm}^{2}$ \\
\hline $450-\mathrm{W}$ & $56 \mathrm{~mW} / \mathrm{cm}^{2}$ & $0.06 \mathrm{~mW} / \mathrm{cm}^{2}$ \\
\hline
\end{tabular}

Besides treating the leachate to reduce the strength of COD, ammonia, and other constituents, it was desired to recover the $\mathrm{TiO} 2$ photocatalysts from the treated water for reuse in future leachate treatment batches. Three commonly used recovery techniques were selected to test for maximum recovery of used Ti02: 1) centrifugation, 2) sedimentation, and 3) filtration.

A centrifuge is a technology that uses rotational force (rpm) in order to increase the gravitational force (G-force) on the product being separated, in this case, treated leachate (centrate). Hamaguchi (2008) showed that up to 80\% of synthesized TiO2 could be recovered from leachate when centrifuged at 4,000 rpm for 25 minutes. However, Coffman (2015) showed that up to $98 \%$ of pre-manufactured (Degussa Aeroxide P25) catalysts could be recovered at 2,000 rpm for 2 minutes.

Sedimentation can be enhanced using a lamella plate system to remove particulate matter from liquids by using a series of inclined plates, which provide effective settling areas in smaller footprints (Coffman, 2015). Figures 3 and 4show examples of the lamella settling tank and the lamella plate media. 


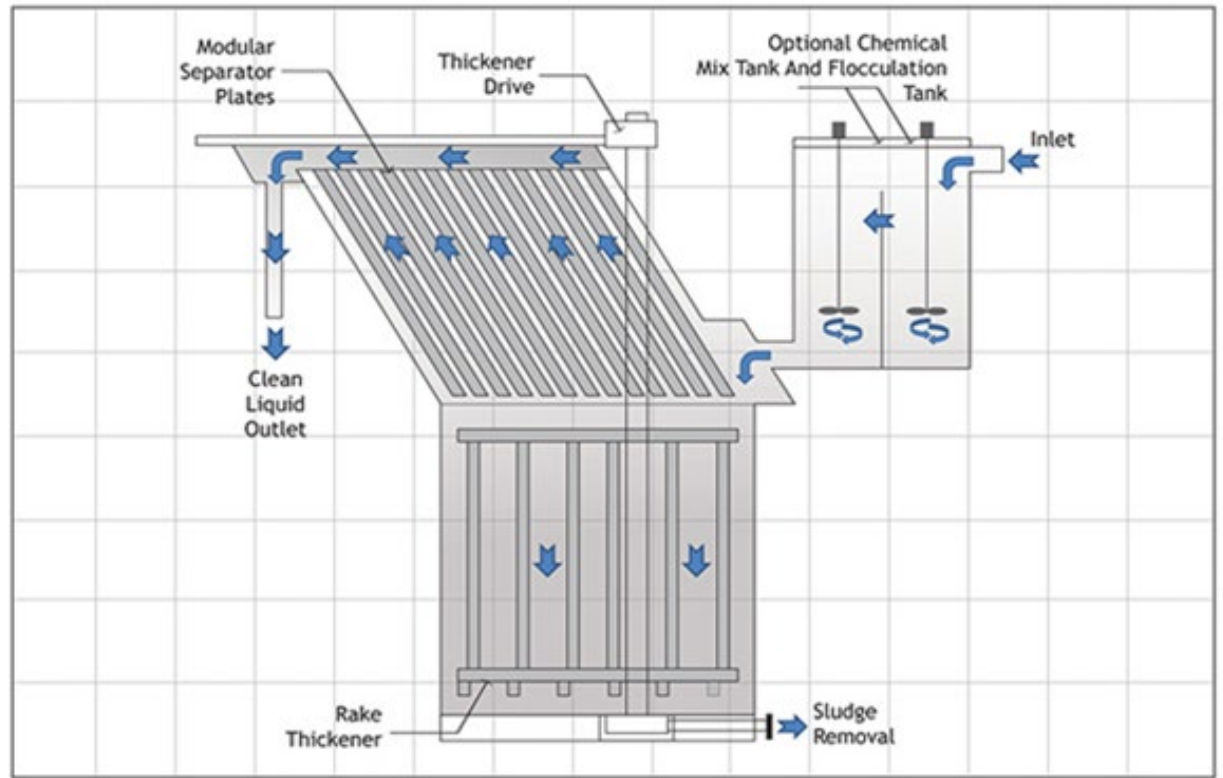

Figure 3: Lamella Plate Clarifier Example

Source: http://www.terraenvironmental.com/Potable-Water-Treatment.html

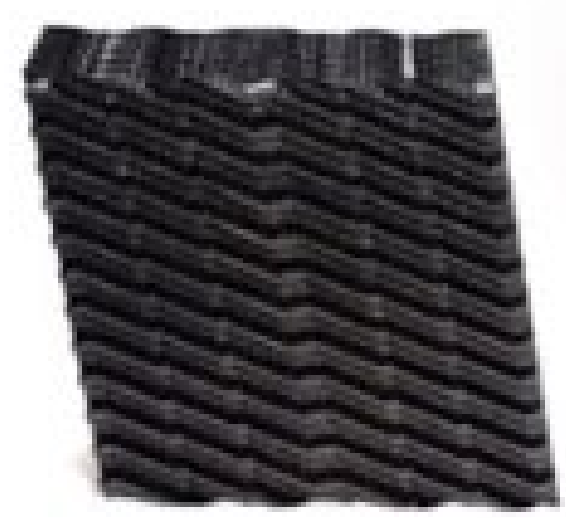

Figure 4: Lamella Plate Media Example

Source: http://www.gea-2h.co.uk/lamella-settlement/

The lamella plate technology will allow the treated leachate and TiO2 to settle by gravity onto the inclined plates or to the bottom of the tank for removal via hopper (McKean, 2010). This kind of sedimentation tank modification can achieve up to $95 \%$ particle recovery, which is more efficient than typical sedimentation basins that achieve $90 \%$ removal of TSS (Parsons, 2006).

Filtration is a size exclusion unit process often involving media such as sand. Media filtration will tend to have effective pore sizes on the order of millimeters or fractions of a millimeter in diameter, but membrane filters have smaller pore sizes (1.5 $\mu \mathrm{m}$ or smaller) (Qasim, 2000). As a result, they can remove smaller sized particles, such as Ti02 photocatalyst nanoparticles $(21 \mathrm{~nm}$ ) (Evonik Industries, 2015). Membrane filters have shown to have relatively low operational costs $(\$ 0.09-\$ 0.14 / 1,000$ gallons of filtrate) (AWWA, 2008), and their average lifespan if maintained properly can be 7 - 12 years (Pinnau, 2008).

In order to test each recovery technology, the leachate and $\mathrm{TiO} 2$ were mixed together at different TiO2 doses $(5$ - $20 \mathrm{~g} / \mathrm{L}$ ), and a treatment test using the optimal parameters from previous work was conducted before running the mixture through the different recovery technologies. Previous experiments conducted at FAU demonstrated that the appropriate conditions for maximum COD and NH3 removal from leachate are: 1) TiO2 dose on the order of 10 $\mathrm{g} / \mathrm{L}$ and UV intensity is on the order of 150-W for a 24 hour exposure in circulation (Meeroff et al. 2012; McBarnette 2011; Youngman, 2013; Lakner, 2015). 
Prior to testing, the dry unused TiO2 was weighed to obtain its pre-weight. After going through treatment and the photocatalyst recovery technologies, the TiO2 was dried in pre-weighted aluminum dishes in a drying oven at $105^{\circ} \mathrm{C}$ for 24 hours to drive off the moisture in the leachate and TiO2 slurry. After 24 hours, the dishes were placed into a desiccator for one hour to come to room temperature. The dry TiO2 was then weighed to get a post weight and determine the percent of $\mathrm{TiO} 2$ that was recovered.

The centrifuge was tested between speeds of 500 - 6,000 rpm. Mixed TiO2 and leachate at doses between 5 and $20 \mathrm{~g} / \mathrm{L}$ were poured into sample tubes in equal volumes and put into the centrifuge for separation.

Sedimentation tests were conducted using graduated cylinders and measuring the settling height over time. From there, the Talmadge and Fitch method (Qasim, 1999) was used to dissect the curve, determine the ultimate settling height, and calculate the appropriate size dimensions for a sedimentation tank based on leachate flows mentioned in Table 1. Figure 5 shows an example of this curve dissection method.

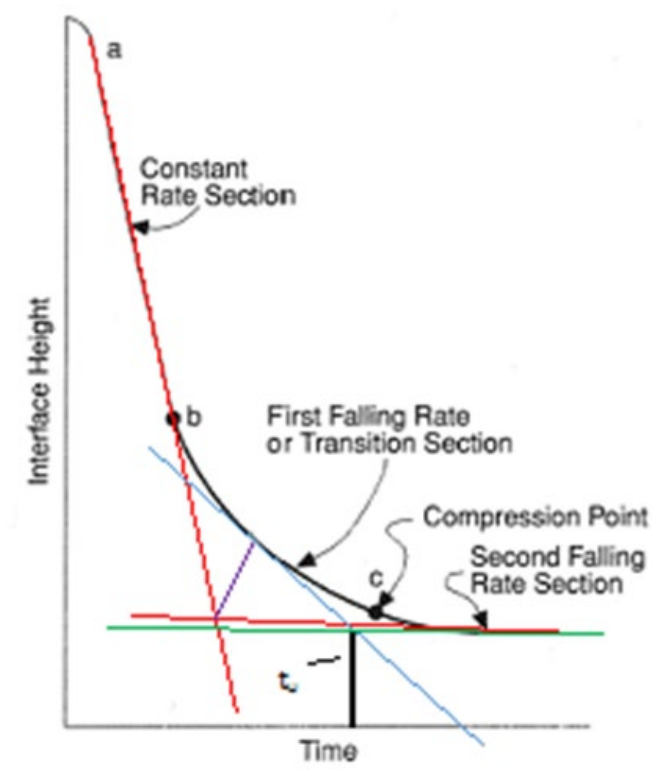

Figure 6: Settling Curve Dissected Using Talmade and Fitch Method

Source: http://www.thermopedia.com/content/1114/

Membrane filters were tested with a bench scale vacuum filter with different sized filter papers with of 1.5 and $0.5 \mu \mathrm{m}$ pore sizes. The mixed $\mathrm{TiO} 2$ and leachate was poured through the filter with the vacuum on. The mixed water and TiO2 was initially poured through the $1.5 \mu \mathrm{m}$ filter paper, and the filtrate was captured in a glass filtration flask. The $1.5 \mu \mathrm{m}$ filtrate was then poured through the $0.5 \mu \mathrm{m}$ paper to capture the remaining TiO2. The initially weighed filter paper was then dried in a drying oven at $105^{\circ} \mathrm{C}$ and weighed to obtain the recovery efficiency of the membrane filter. 6 shows an example of the experimental setup.

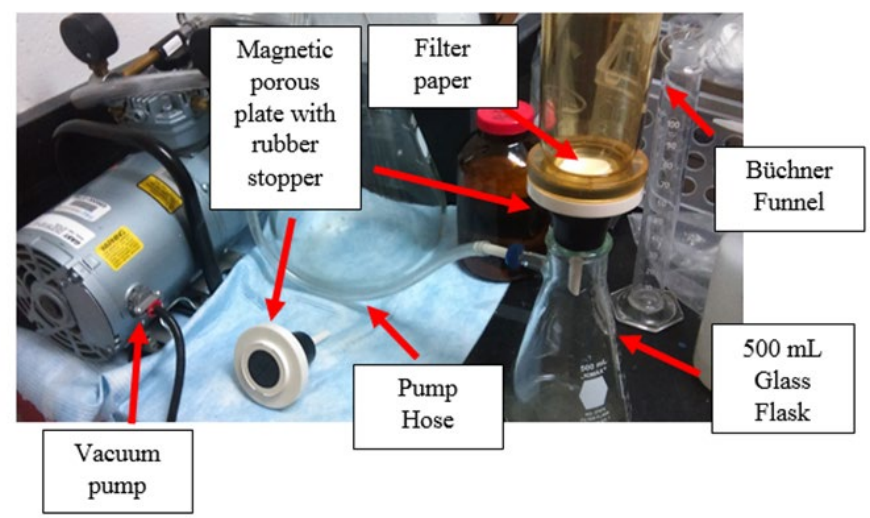

Figure 6: Filtration Setup (Coffman, 2015) 


\section{RESULTS AND DISCUSSION}

The results for treating leachate for the parameters of COD and NH3 via both the falling film and flow-through reactors is summarized in Table 5.

Table 5: COD and Ammonia Removal Comparison for 150-W and 450-W

\begin{tabular}{|c|c|c|c|c|c|c|c|c|c|c|}
\hline $\begin{array}{c}\mathrm{TiO}_{2} \\
\mathrm{Dose} \\
(\mathrm{g} / \mathrm{L})\end{array}$ & Type of Reactor & $\begin{array}{c}\text { Lamp } \\
(\mathrm{W})\end{array}$ & $\begin{array}{c}\text { Avg. Temp. } \\
\left({ }^{\circ} \mathrm{C}\right)\end{array}$ & $\begin{array}{c}\text { Avg. } \\
\mathrm{pH}\end{array}$ & $\begin{array}{c}\mathrm{COD} \\
(\mathrm{mg} / \mathrm{L} \text { as } \\
\left.\mathrm{O}_{2}\right)\end{array}$ & $\begin{array}{c}\mathrm{COD}_{\mathrm{f}} \\
(\mathrm{mg} / \mathrm{L} \text { as } \\
\left.\mathrm{O}_{2}\right)\end{array}$ & $\begin{array}{c}\mathrm{COD} \% \\
\text { Removal }\end{array}$ & $\begin{array}{c}\mathrm{NH}_{3}-\mathrm{N}_{\mathrm{o}} \\
(\mathrm{mg} / \mathrm{L} \\
\mathrm{as} \\
\mathrm{N})\end{array}$ & $\begin{array}{c}\mathrm{NH}_{3}-\mathrm{N}_{\mathrm{f}} \\
(\mathrm{mg} / \mathrm{L} \text { as } \\
\mathrm{N})\end{array}$ & $\begin{array}{c}\mathrm{NH}_{3}-\mathrm{N} \\
\%\end{array}$ \\
\hline 5 & Falling Film & 150 & 9.6 & 8.0 & 341 & 300 & 12 & 313 & 116 & 63 \\
\hline 5 & $\begin{array}{c}\text { Falling } \\
\text { Film }\end{array}$ & 450 & 19.7 & 8.5 & 341 & 255 & 25 & 313 & 243 & 23 \\
\hline 5 & Flow Through & 450 & 27.5 & 9.0 & 255 & 235 & 8 & 243 & 133 & 45 \\
\hline 5 & Flow Through & 150 & 13.1 & 8.6 & 300 & 225 & 25 & 232 & 193 & 17 \\
\hline 10 & $\begin{array}{c}\text { Flow } \\
\text { Through Aerated }\end{array}$ & 450 & 23.0 & 8.6 & 239 & 197 & 18 & 100 & 75 & 25 \\
\hline 5 & $\begin{array}{c}\text { Flow Through } \\
\text { Aerated }\end{array}$ & 150 & 18.8 & 8.7 & 268 & 245 & 9 & 135 & 119 & 12 \\
\hline
\end{tabular}

These experiments demonstrate that the 450-W lamp provides slightly better COD removal in the falling film reactor over the $150-\mathrm{W}$ lamp, but the $150-\mathrm{W}$ performed better for ammonia removal. However, T-tests found no evidence of statistically significant differences between lamps. In comparing all of the experiments, the 450-W lamp had an increase in average removal of 25\%; however, this may be attributed to the higher temperatures and not necessarily the lamps. Both lamps created excessive scaling on the reactor's lens that physically blocked UV radiation and diminished the penetration of UV light that the TiO2 received in the reactor. The primary cause of the scaling is the heat radiating from the lamp, which readily precipitated calcium carbonate from the leachate. An improvement of actively cooling the lamp decreased the scaling, enabling light to pass more easily through the lens, but minor scaling was still observed in long term exposures (Meeroff, 2016).

The recovery of TiO2 involved three methods: centrifuge, sedimentation, and filtration testing to determine the TiO2 recovery efficiency. The centrifuge was run at 2,000, 4,000, and 6,000 rpm. Figure 8 shows the recovery for each. The 2,000 rpm speed showed the smallest loss.

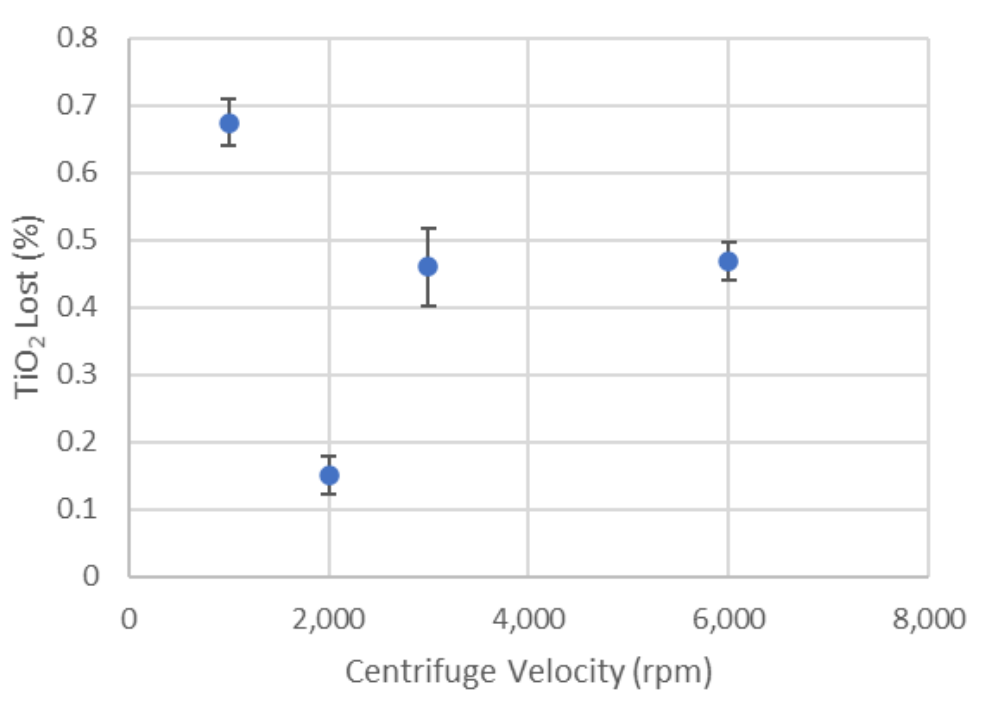

Figure 8: Centrifuge Test $42-49$ TiO2 Centrifuge Test Results at 2 minutes

Source: Coffman, 2015 
The centrifuge operated for 1, 2, 4, 6 and 10 minutes. As noted in Figure 9, two minutes produced the best TiO2 recovery results, and it was the "breaking point" time. The standard deviation error bars show the range of the average data for each centrifuge time.

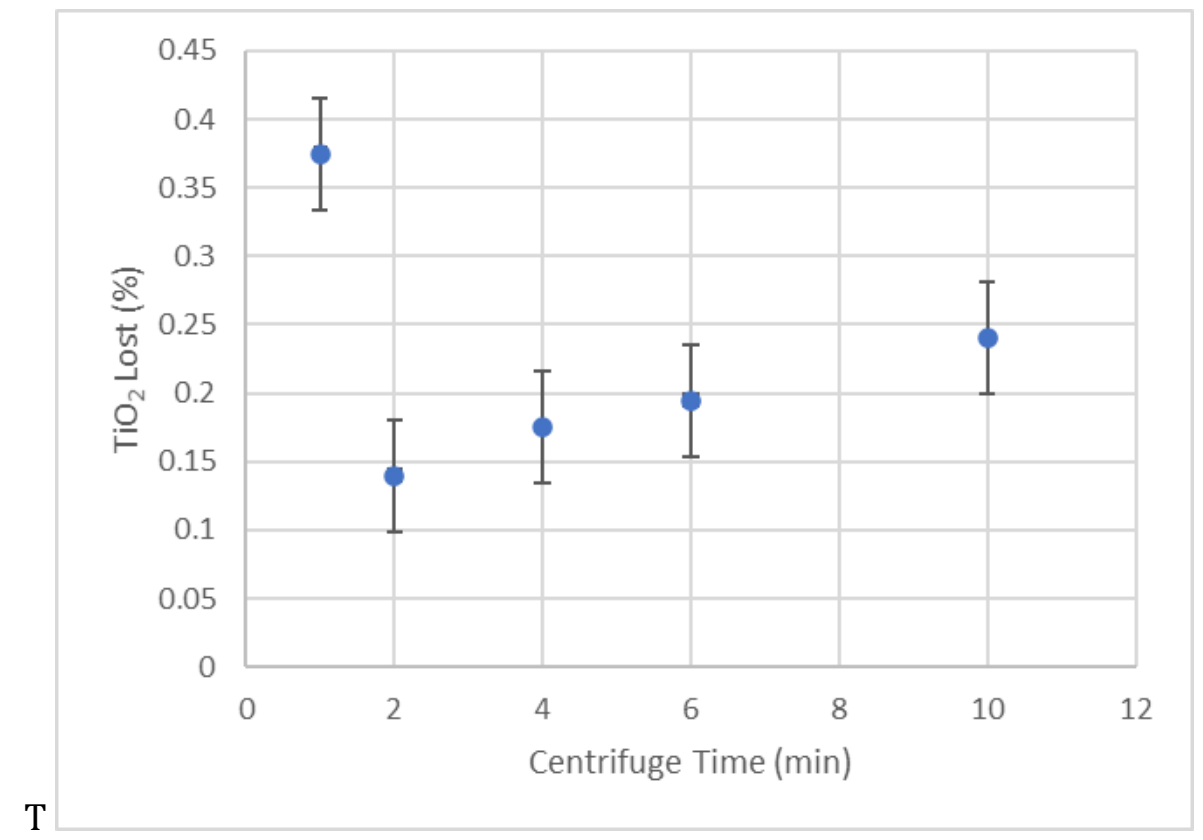

Source: Coffman, 2015

Figure 9: Centrifuge Test $32-41$ TiO2 Centrifuge Test Results at 6,000 rpm

Figure 10 shows the settling curves for the four different TiO2 doses settled 3g, 5g, 7.5g, and 10g/100 mL, respectively with their slopes for type one settling. Table 22 shows the average ultimate settling times, and Table 23 shows the ultimate settling heights for these four doses.

Figure 11 shows the settling curves for the four different TiO2 doses settled 3g, 5g, 7.5g, and 10g/100 mL, respectively with their slopes for type one settling. Settling times were set at 3, 5, 7 an d0 minutes. Figure 11 shows that the longer the settling time, the more settled.

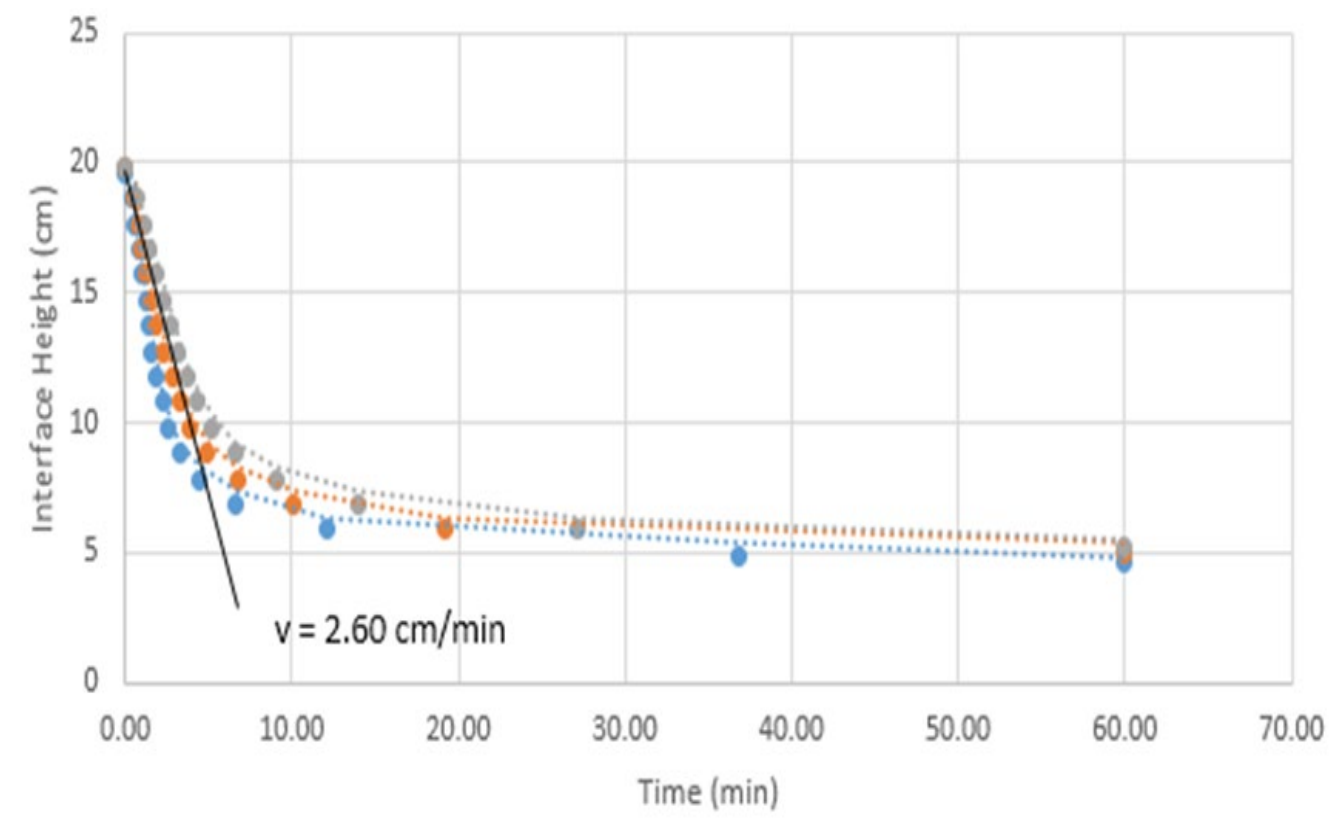

Figure 10: 3g/100 mL Combined Settling Curves Source: Coffman, 2015 
Photocatalytic Oxidation of Landfill Leachate Using Uv/Tio2 With Catalyst Recovery

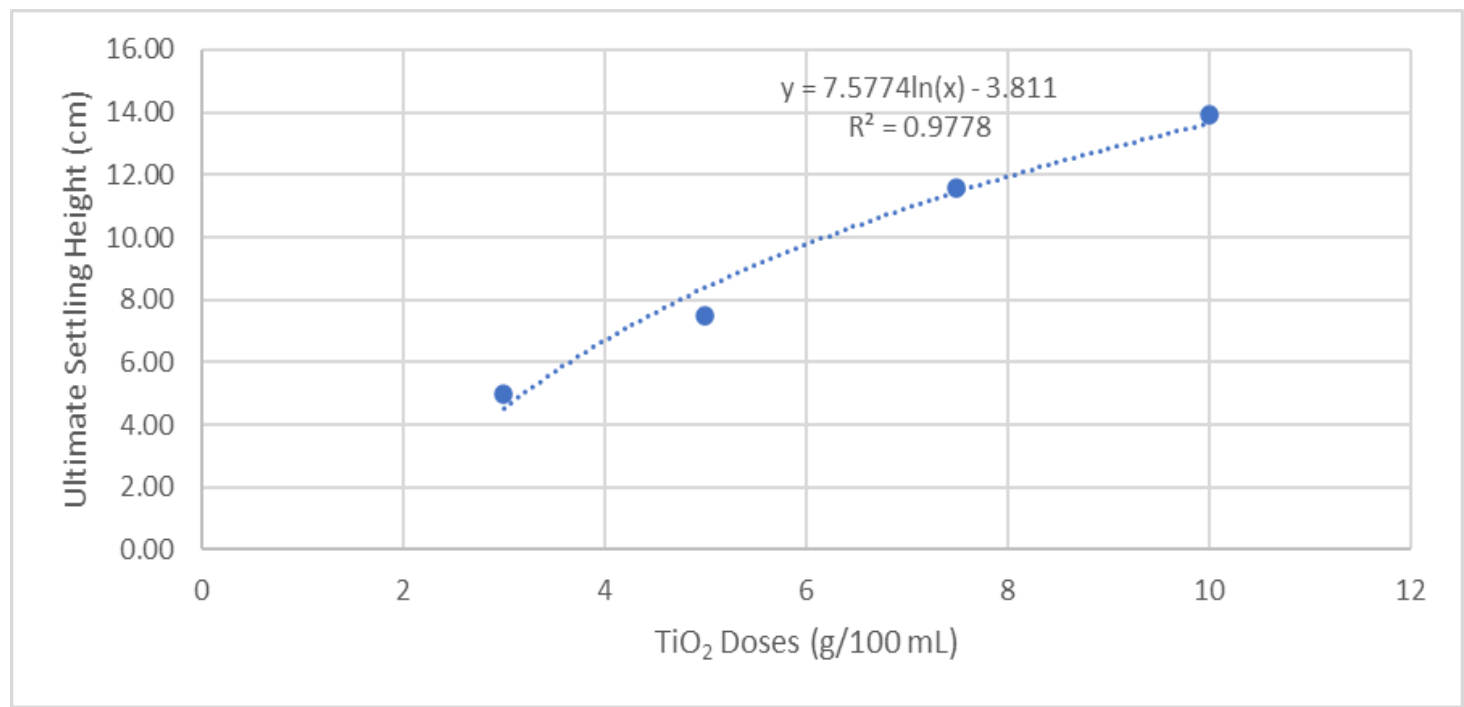

Source: Coffman, 2015

Figure 11: TiO2 Ultimate Settling Height Logarithmic Trends

The filter recovery tests were used to determine how much initial TiO2 was retained using $1.5 \mu \mathrm{m}$ and $0.5 \mu \mathrm{m}$ filters at the different TiO2 doses of $5 \mathrm{~g} / \mathrm{L}, 10 \mathrm{~g} / \mathrm{L}, 15 \mathrm{~g} / \mathrm{L}$, and $20 \mathrm{~g} / \mathrm{L}$. Table 28 shows the recovery results of the filters at different doses, and Figure 49 shows the average results plotted in a bar graph with the standard deviations set as the error bar dimensions.

Table 6: Summary of Filter TiO2 Recovery Results

\begin{tabular}{|c|c|c|c|c|c|}
\hline \multirow{2}{*}{$\mathrm{TiO}_{2}$ Dose (g/L) } & \multicolumn{3}{|c|}{$\mathrm{TiO}_{2}$ Recovered (\%) } & Average $\mathrm{TiO}_{2}$ Recovered (\%) & SD (\%) \\
\cline { 2 - 4 } & Trial 1 & Trial 2 & Trial 3 & & \\
\hline 5 & $100.4 \%$ & $99.6 \%$ & $95.9 \%$ & $98.6 \%$ & $2.41 \%$ \\
\hline 10 & $98.5 \%$ & $97.0 \%$ & $96.8 \%$ & $97.4 \%$ & $0.91 \%$ \\
\hline 15 & $98.3 \%$ & $97.7 \%$ & $96.3 \%$ & $97.4 \%$ & $1.03 \%$ \\
\hline 20 & $98.0 \%$ & $95.8 \%$ & $95.1 \%$ & $96.3 \%$ & $1.51 \%$ \\
\hline
\end{tabular}

Plotting the results and trends of this data, the strength of the trends can be seen by their R2 values, and the standard deviation error bars show the range of the average data for each TiO2 dose. These can be seen in Figure 12.

Source: Coffman, 2015

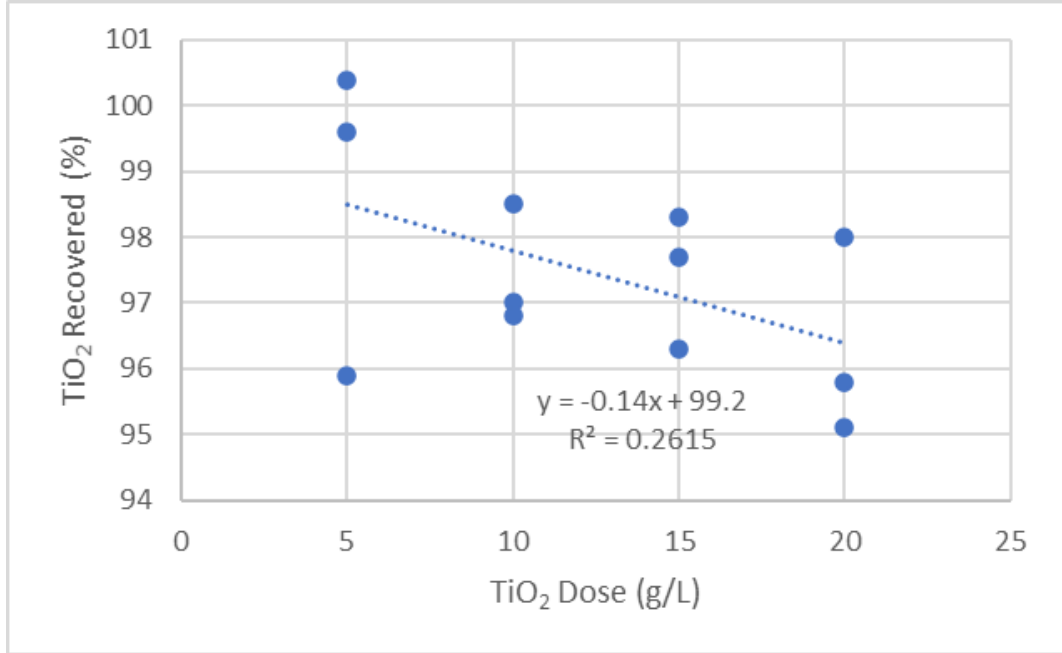

Figure 12: Filter TiO2 Dosage Recovery Results 
Regarding the recovery of TiO2 catalyst particles after their use for leachate treatment, the efficiencies between the centrifuge, sedimentation tank, and filters are shown in Figure 13. The centrifuge was determined to be the most efficient TiO2 recovery technology.

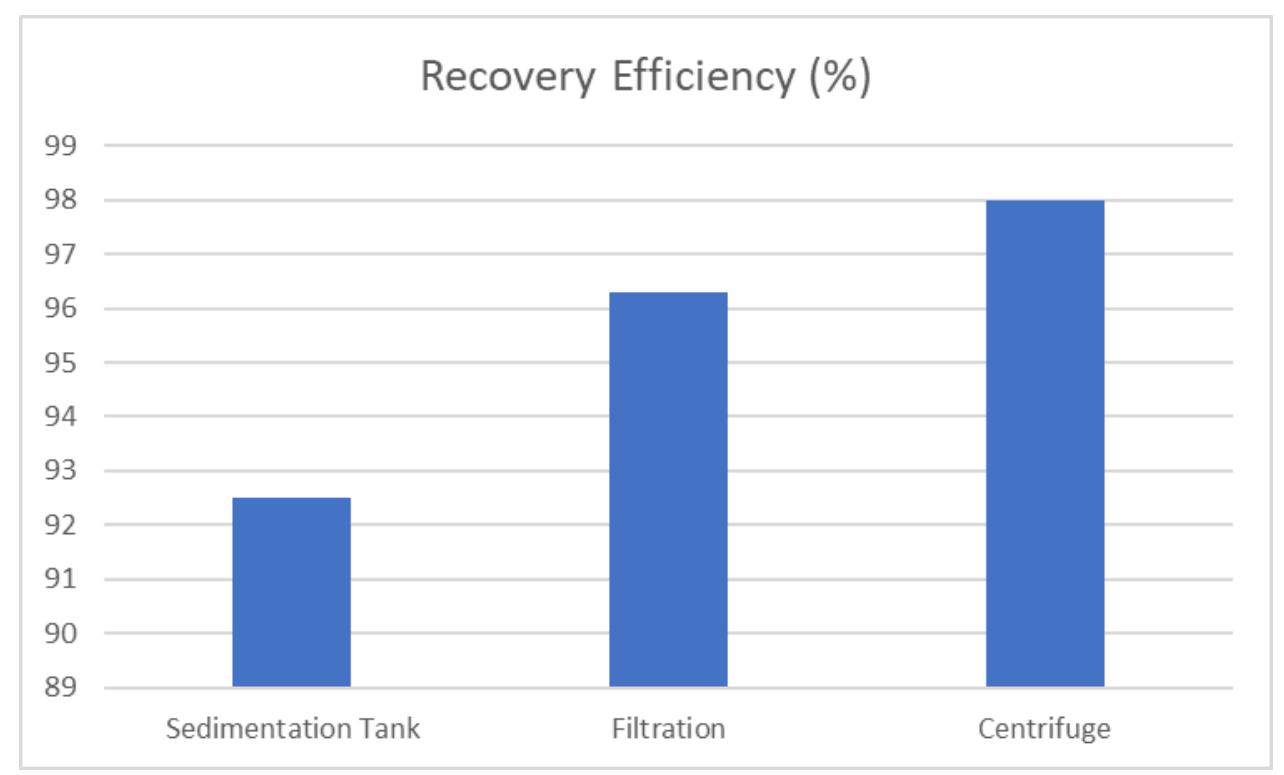

Figure 13: Comparison of the TiO2 Recovery Technologies (Coffman, 2015)

\section{CONCLUSION}

It has been determined that effective treatment of leachate to acceptable wastewater discharge standards can be achieved via photocatalytic oxidation treatment (McBarnette, 2011; Lakner, 2015; Youngman, 2013; Meeroff, 2014). However, when determining the capital and operation and maintenance (O\&M) costs for treating the leachate, the costs were about $\$ 280 / 1,000$ gallons (???, Meeroff, 2016), which is not competitive. This is largely due to the replacement costs of TiO2 and the initial capital costs (Meeroff, 2016).

When determining the capital and operation and maintenance $(0 \& M)$ costs for the centrifuge recovery, it was determined to be about $\$ 2.08 / 1,000$ gallons. This cost will fluctuate based on the leachate flow, but the $0 \& M$ costs are very low $<\$ 0.50 / 1,000$ gallons. Table 8 shows a breakdown of the lifecycle costs over 20 years based on a leachate flow of 112,000 gallons per month (Coffman, 2015).

Table 7: Centrifuge Lifecycle Costs

\begin{tabular}{|c|c|c|c|}
\hline *Installed Capital Cost & Units & Unit Cost & $\begin{array}{c}\text { Total Cost } \\
(\$ / 1,000 \text { gallons })\end{array}$ \\
\hline Centrifuges \& Piping & 8 & $\$ 5,500$ & 1.65 \\
\hline 0\&M Costs & & & \\
\hline Electricity & 8 & $\$ 0.049 /(\mathrm{kWhr})$ & 0.38 \\
\hline Maintenance & 7 & $10 \%$ of Capital & 0.05 \\
\hline Total Cost & & & 2.08 \\
\hline
\end{tabular}

The treatment of leachate with the photocatalytic process has to be cost effective for it to be adopted industry wide. Based on the kinetic reaction rate the cost was calculated for treating the Dyer Park leachate to surface discharge goal. This treatment would be limited by the ammonia removal taking 185 hours. The generation rates are based on the average volume for Dyer Park of 117,000 gallons a month. However, the treatment was designed for the maximum volume of 500,000 gallons a month. Electrical costs were based on the number of lamps and pumps. The ratio of reservoir sized to number of lamps was decreased by 100, expecting the increase in scale to allow for an increase in the falling film reactor size. 
Two different cost were calculated, Table 51 is the cost of treatment using the photocatalytic process for 185 hours with $10 \mathrm{~g} / \mathrm{L}$ of $\mathrm{TiO} 2$ in the reactor. The capital cost was spread out over 20 years at a $6 \%$ interest rate. The cost to treat leachate with this method is $\$ 280.99$ per 1000 gallons.

Table 55: Cost to Reuse TiO2

\begin{tabular}{|c|c|c|c|}
\hline Capital Cost & Units & Unit Cost & Total Cost \\
\hline $\mathrm{TiO}_{2}$ chemical costs & 504 & $\$ 1,390$ & $\$ 700,560$ \\
\hline 150,000 Gallon Tank & 2 & $\$ 225,000$ & $\$ 450,000$ \\
\hline UV lamps/ballast/lens & 504 & $\$ 2,000$ & $\$ 1,008,000$ \\
\hline Pumps/blowers/plumbing/etc. & $\$ 2$ & $\$ 50,000$ & $\$ 100,000$ \\
\hline Total capital cost & & & $\$ 2,258,560$ \\
\hline O\&M costs & & & \\
\hline Electric (\$0.12/kW-hr) & 12 & $\$ 8,000$ & $\$ 96,000$ \\
\hline Employees & 12 & $\$ 16,000$ & $\$ 192,000$ \\
\hline Maintenance & & & $\$ 23,614$ \\
\hline Total 0\&M & & & $\$ 311,615$ \\
\hline Annualized (6\%, 20 years) & 12 & $\$ 16,181$ & $\$ 194,172$ \\
\hline Total annual costs & & & $\$ 505,787$ \\
\hline Cost per 1000 gallons (1.8 million gallons) & & & $\$ 280.99$ \\
\hline
\end{tabular}

The second cost is for pre-treatment with settling of $30 \mathrm{~g} / \mathrm{L}$ of TiO2, then treatment with $10 \mathrm{~g} / \mathrm{L}$ of TiO2. The breakdown of cost can be seen in Table 52, the continuous replacement of Ti02 greatly increase the cost of treatment. The cost to treat 1000 gallons would be $\$ 24,320.59$, this is directly related to the cost of TiO2, 1000 gallons is 3800 liters and the dose is $40 \mathrm{~g} / \mathrm{L}$ means that $152 \mathrm{~kg}$ of TiO2 is needed. The current cost of nano TiO2 in bulk is $\$ 139 / \mathrm{kg}$, the cost just for TiO2 is $\$ 18,916.01$.

\section{SOURCES OF FUNDING}

None.

\section{CONFLICT OF INTEREST}

None.

\section{ACKNOWLEDGMENT}

None.

\section{REFERENCES}

[1] Bhardwaj, Vipin. "Diatomaceous Earth Filtration for Drinking Water." National Drinking Water Clearinghouse, 2001, Page 2.

[2] Burton, Franklin. "Suspended Growth Biological Processes." In Wastewater Engineering: Treatment and Reuse, 820 - 826. 4th ed. Crawfordsville, IN: McGraw-Hill Companies, 2003.

[3] Cheremisinoff, Nicholas P. (2002). "Chapter 8". Handbook of water and wastewater treatment technologies ([Online-Ausg.] ed.). Boston: Butterworth-Heinemann.

[4] Cho, I. H., Moon, I. Y., Chung, M. H., Lee, H. K., \& Zoh, K. D. (2002). Disinfection effects on E. coli using TiO2/UV and solar light system. Water Science and Technology: Water Supply, 2(1), 181-190.

[5] Cleland, A.J. "Determination of Shape of Kaolin Pigment Particles." Clay Minerals, 1992, Page 504.

[6] Coffman, N. (2015). Recovering titanium dioxide ( $\mathrm{TiO} 2$ ) after its useto treat leachate for reuse on future leachate flows. (Masters thesis, Florida Atlantic University). 
Neil Coffman, Daniel Meeroff, and Frederick Bloetscher

[7] De Morais, J. L., \& Zamora, P. P. (2005). Use of advanced oxidation processes to improve the biodegradability of mature landfill leachates. Journal of Hazardous Materials, 123(1-3), 181-186.

[8] Dey, Tania. "Photocatalytic Degredation of Poorl Biodegradable Water Pollutions Using Titania (Ti02) Nanoparticles." In Nanotechnology for Water Purification, Page 118 - 119. Boca Raton, FL: BrownWalker Press, 2012.

[9] Fang, H. H. P., Lau, I. W. C., \& Wang, P. (2005). Anaerobic treatment of Hong Kong leachate followed by chemical oxidation. Water science and technology, 52(10-11), 41-49.

[10] Farrah, S.R. "Use of Modified Diatomaceous Earth for Removal and Recovery of Viruses in Water." Applied and Environmental Microbiology, 1991, Page 2504.

[11] Feitz, Andrew J., T. David Waite, Gary J. Jones, Brace H. Boyden, and Philip T. Orr. "Photocatalytic degradation of the blue green algal toxin microcystin-LR in a natural organic-aqueous matrix." Environmental science \& technology 33, no. 2 (1999): 243-249.

[12] Foo, K. Y., \& Hameed, B. H. (2009). An overview of landfill leachate treatment via activated carbon adsorption process. Journal of hazardous materials, 171(1-3), 54-60.

[13] Greenwood, R; Kendall, K. "Electroacoustic studies of moderately concentrated colloidal suspensions". Journal of the European Ceramic Society 19 (4) (1999). Page 479-488.

[14] Hamaguchi, Hatsuko. "Investigation of Options for Long-Term Leachate Management." 2008, Page 17.

[15] Hemond, Harold. Chemical Fate and Transport in the Environment. 3rd ed. Vol. 1. San Diego, CA: Elsevier, 2015. Page 4-6, 62, 129-131.

[16] Ibanez, Jorge. "Environmental Chemistry." In Alkalinity and Buffering Capacity of Water, Page 28-29. New York City, NY: Springer New York, 2008.

[17] Kirby, B.J. Micro- and Nanoscale Fluid Mechanics: Transport in Microfluidic Devices. Cambridge University Press (2010).

[18] Lakner, J. (2015). Safe Discharge of Landfill Leachate to the Environment. (Masters Thesis, Florida Atlantic University).

[19] Lema, J. M., Mendez, R., \& Blazquez, R. (1988). Characteristics of landfill leachates and alternatives for their treatment: a review. Water, Air, and Soil Pollution, 40(3-4), 223-250.

[20] Li, Wengbing. "pH-responsive, TiO2-Attached Porphyrin for Singlet Oxygen Production in an Aqueous Solution." Applied Materials and Interfaces 1, no. 8 (2009). Page 1781. Accessed October, 2015. http://www.ncbi.nlm.nih.gov/pubmed/20209036.

[21] McBarnette, A. (2011). Treatment of Landfill Leachate Via Advanced Oxidation (Doctoral dissertation, Florida Atlantic University).

[22] Meeroff, D. E., \& Teegavarapu, R. (2010). Interactive decision support tool for leachate management. Gainesville, FL: Hinkley Center for Solid and Hazardous Waste Management. http://www. hinkleycenter. org/images/stories/Meeroff_INTERACTIVE_DECISION_SUPPORT_TOOL.pdf.

[23] Meeroff, D. E., Bloetscher, F., Reddy, D. V., Gasnier, F., Jain, S., McBarnette, A., \& Hamaguchi, H. (2012). Application of photochemical technologies for treatment of landfill leachate. Journal of hazardous materials, 209, 299-307.

[24] Meeroff, D. E., Lakner, J., Shaha, B., Walecki, E., Harris, A., \& Meyer, L. (2016). Futuristic On-Site Leachate Management. In World Environmental and Water Resources Congress 2016 (pp. 1-10).

[25] Meeroff, D. E., \& Lakner, J. (2014). Safe Discharge of Landfill Leachate to the Environment. Final Report for the William W.“Bill” Hinkley Center for Solid and Hazardous Waste Management, Gainesville, FL. Report.

[26] Meeroff, D. E., Lakner, J., \& Coffman, N. (2016). Safe Discharge of Landfill Leachate to the Environment Year 2 Final Report.

[27] Mendez-Novelo, R. I., Castillo-Borges, E. R., Sauri-Riancho, M. R., Quintal-Franco, C. A., Giacoman-Vallejos, G., \& Jimenez-Cisneros, B. (2005). Physico-chemical treatment of Merida landfill leachate for chemical oxygen demand reduction by coagulation. Waste management \& research, 23(6), 560-564.

[28] Munter, R. (2001). Advanced oxidation processes-current status and prospects. Proc. Estonian Acad. Sci. Chem, 50(2), 59-80.

[29] Parsons, Simon A.; Jefferson, Bruce (2006). "Chapter 4". Introduction to potable water treatment processes. Ames, Iowa: Blackwell Pub. Accessed June, 2015. 
[30] Parsons, Simon A.; Jefferson, Bruce (2006). "Chapter 4". Introduction to potable water treatment processes. Ames, Iowa: Blackwell Pub.

[31] Peyton, G. R., \& Glaze, W. H. (1988). Destruction of pollutants in water with ozone in combination with ultraviolet radiation. 3. Photolysis of aqueous ozone. Environmental science \& technology, 22(7), 761-767.

[32] Pinnau, Ingo. "Membranes for Water Treatment: Properties and Characterization." 2008, Page 18.

[33] Piscopo, Antoine. "Influence of $\mathrm{pH}$ and Chloride Anion on the Photocatalytic Degradation of Organic Compounds Part I. Effect on the Benzamide and Para-hydroxybenzoic Acid in TiO2 Aqueous Solution." Applied Captalysis 35, no. 2 (2001). Page 119. Accessed May, 2015. http://www.sciencedirect.com/science/article/pii/S0926337301002442.

[34] Qasim, Syed. "Biological Waste Treatment." In Wastewater Treatment Plants: Planning, Design, and Operation, Page 449-450. Boca Raton, FL: CRC Press LLC, 1999.

[35] Qasim, Syed. "Sedimentation." In Water Works Engineering: Planning, Design, and Operation, Page 302-303, 307. Upper Saddle River, NJ: Pearson Education, 2000.

[36] Renou, S., Givaudan, J. G., Poulain, S., Dirassouyan, F., \& Moulin, P. (2008). Landfill leachate treatment: review and opportunity. Journal of hazardous materials, 150(3), 468-493.

[37] Schulte, P., Bayer, A., Kuhn, F., Luy, T., \& Volkmer, M. (1995). H202/O3, H2O2/UV and H2O2/Fe2+ processes for the oxidation of hazardous wastes.

[38] Thiruvenkatachari, Ramesh. "A Review on UV/TiO2 Photocatalytic Oxidation Process." Korean J. Chemical Engineering, 2008, Page 69-70.

[39] Witharana, Sanjeeva. "Aggregation and Settling in Aqueous Polydisperse Alumina Nanoparticle Suspensions." Journal of Nanoparticle Research, 2012, Page 9.

[40] Youngman, F. (2013). Optimization of TiO2 photocatalyst in an advanced oxidation process for the treatment of landfill leachate. (Masters thesis, Florida Atlantic University). 